\title{
Mineralogia e geoquímica da ocorrência de palygorskita de Alcântara, bacia de S. Luís-Grajaú, Maranhão
}

\section{(Mineralogy and geochemistry of occurrence of palygorskite of Alcântara, S. Luís-Grajaú basin, Maranhão, Brazil)}

\author{
K. B. Amorim, R. S. Angélica \\ Instituto de Geociências, Laboratório de Caracterização Mineral, Universidade Federal do Pará, Rua Augusto \\ Corrêa, s/n,66075-110 Belém, PA, Brasil \\ Kamilla.amorim@hotmail.com,angelica@ufpa.br
}

\begin{abstract}
Resumo
A Formação Alcântara (bacia de São Luis-Grajaú, região de Alcântara, MA) é constituída por pelitos, arenitos e dolomitos. Esses litotipos representam uma sucessão progradacional de depósitos de laguna/washover e canal de maré sobrepondo-se a depósitos de shoreface gerados por processos de tempestade. O presente trabalho tem como objetivo principal à caracterização mineralógica e geoquímica dos argilominerais que ocorrem nos níveis pelíticos da Formação Alcântara, especialmente a palygorskita. Foi descrito e amostrado um perfil geológico na praia da Baronesa, na cidade de Alcântara, MA, no qual foram coletadas 8 amostras, que após a preparação em laboratório, foram submetidas a análises mineralógicas e químicas por difração de raios X, fluorescência de raios $\mathrm{X}$, análises térmicas e microscopia eletrônica de varredura. Os resultados mostraram que o perfil da praia da Baronesa é composto por arenitos na base, seguido de pelitos dominantes, com intercalações de dolomitos. Nos pelitos, foram descritos uma ampla assembléia de argilominerais, em ambiente lagunar, com variações no conteúdo de palygorskita, clorita, illita, esmectita e traços de caulinita. Observam-se ainda traços de dolomita, calcita e feldspatos. Os teores de palygorskita e dolomita (níveis dolomíticos) são acentuados, sugerindo que as condições climáticas durante o período de deposição foram áridas a semi-áridas. Duas gerações de palygorskita foram descritas: uma na forma de bolsões ou acumulações macroscópicas nos níveis pelíticos ricos em esmectita, freqüentemente descritas na literatura, e outra na forma maciça, como o mineral dominante dos níveis pelíticos superiores do perfil da praia da Baronesa. Essa segunda geração está sendo descrita pela primeira vez, neste trabalho, podendo constituir em níveis métricos e que podem revelar interesse econômico.
\end{abstract}

Palavras-chave: Alcântara, palygorskita, argilominerais, esmectita, minerais industriais.

Abstract

The Alcântara Formation (S. Luis-Grajaú Basin, Alcântara region, northern Brazil) is mainly constituted by mudstones, sandstones and limestones. These lithotypes represent a progradacional succession of lagun/washover and tidal channel deposits that overlap huge shoreface deposits. The main purpose of this work is to carry out a mineralogical and geochemical characterization of the clay minerals association related to the pelitic rocks of the Alcantara Formation, specially the known palygorskite occurrences. One geological profile was sampled (eight samples) and described at the Baronesa beach (Alcântara city). The samples were submitted to mineralogical and chemical analysis by means of the following techniques: X-ray diffraction, X-ray fluorescence, thermal analysis (TG-DTA) and scanning electron microscopy. The results showed that the Baronesa Beach profile is mainly composed by sandstones at the base, followed by mudstones with intercalations of limestones. A wide clay mineral assemblage was described in a lagoon environment, with different contents of palygorskite, chlorite, illite, smectite and traces of kaolinite. Small amounts of dolomite, calcite and feldspars were also observed. The genesis of these minerals assemblage are mainly related to arid to semi-arid climatic conditions during the deposition period, with high evaporation rates. Two generations of palygorskite were described: (1) white macroscopic accumulations easily observed in the field and frequently described in the literature; and (2) massive accumulation, as the dominant mineral, in the upper muddy levels of the Baronesa Beach profile. This second generation is described for the first time in this work, and may constitute metric levels with potential economic interest.

Keywords: Alcântara, Palygorskite, clay minerals, smectite, industrial minerals.

\section{INTRODUÇÃO}

A sucessão sedimentar da Formação Alcântara encontrase muito bem exposta em afloramentos na porção central e norte da Bacia de São Luis-Grajaú, no município de Alcântara, MA (Fig. 1). Nesta região a fácies lagunar da formação anteriormente citada é marcada por uma grande quantidade de pelitos, cuja mineralogia é marcada por argilominerais magnesianos. Dentre esses minerais, já era do conhecimento na literatura a ocorrência restrita de palygorskita [1]. A identificação em campo é muito simples, pois se trata de acumulações centimétricas, esbranquiçadas 
e com uma textura típica assemelhando-se a "papelão molhado". Durante os trabalhos de campo para a realização desta pesquisa, surpreendentemente, além das ocorrências pontuais anteriormente descritas, foram descobertos níveis métricos constituídos dominantemente de palygorskita, aparentemente, com grande extensão lateral e possibilidade de aproveitamento econômico. Vale ressaltar que há poucas ocorrências de palygorskita no Brasil, com apenas duas minas em produção, do Grotão do Angico e Boa Vista, ambas no município de Guadalupe, no Piauí [2]. Segundo o comitê de nomenclatura de argilominerais da AIPEA (Associação Internacional para o estudo de Argilas) [3] a palygorskita é classificada como um argilomineral não planar, do tipo $2: 1$, que pertence ao grupo das hormitas. É um silicato complexo de magnésio, que apresenta uma estrutura em canal aberto, formando cristais alongados e geralmente com aspecto fibroso. Pode apresentar substituições isomórficas parciais do magnésio pelo alumínio e/ou ferro, caracterizando-se como uma estrutura cristalina semelhante aos anfibólios. Apresenta inúmeras aplicações industriais, com destaque para fluidos de perfuração, cat litter, carreadores na agricultura, absorventes industriais entre outros.

O objetivo principal deste trabalho é apresentar o que se considera uma nova ocorrência de palygorskita no Brasil, seu contexto geológico e os resultados da caracterização química e mineralógica dos argilominerais, em especial da palygorskita, dos níveis pelíticos da Formação Alcântara.

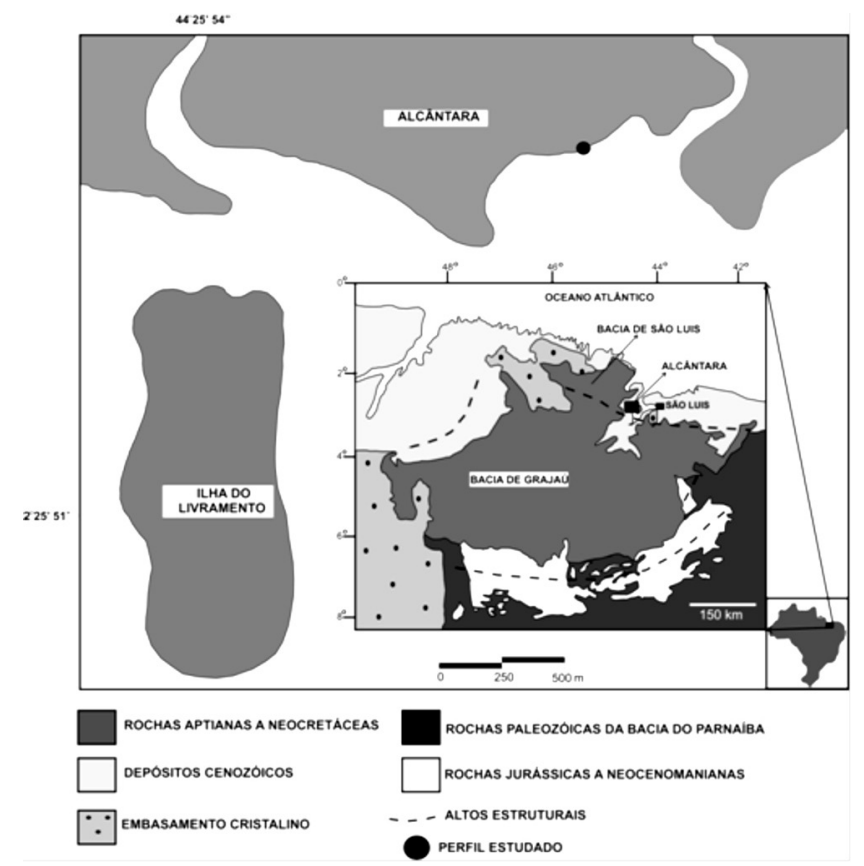

Figura 1: Mapa de localização da área de estudo [4].

[Figure 1: Location map of the studied area [4].]

\section{Contexto geológico}

A geologia da área de estudo restringe-se aos litotipos da Formação Alcântara, que representa a porção inferior a intermediária do Grupo Itapecuru, que ocorre na Bacia de São Luis-Grajaú. Esta Formação é constituída por pelitos de coloração esverdeada a avermelhada com algumas lentes de areia muito fina e silte, além de dolomitos de coloração cinza-esbranquiçada com muitas feições de bioturbação, superfícies microcársticas e brechas geradas por ressecamento. Ocorrem ainda arenitos de coloração esverdeada e avermelhada cuja granulometria varia de fina a grossa, que exibem diversas estruturas como laminações cruzadas cavalgantes, estratificações cruzadas de grande porte, estratificações cruzadas do tipo swaley, além de laminações sigmoidais e tangenciais. Esses litotipos representam uma sucessão progradacional com depósitos da laguna/washover e canal de maré sobrepondo-se a depósitos de shoreface gerados por processos de tempestade de grande intensida $[5,6]$.

\section{MATERIAIS E MÉTODOS}

Foram descritos e amostrados dois perfis na área de trabalho: um na praia da Baronesa e outro na ilha do Livramento (Fig. 1). Apenas o primeiro apresentou maior relevância, devido ao seu conteúdo rico em argila, principalmente com relação ao conteúdo de palygosrkita. $\mathrm{O}$ perfil da ilha do Livramento mostrou-se mais arenoso, com apenas ocorrências pontuais deste mineral. Oito amostras (B-1, B-2, B-3, B-4, B-5, B-6, B-7, B-8) foram coletadas na falésia da praia da Baronesa, com quantidade aproximada de $3 \mathrm{~kg}$. Adicionalmente, foi coletada uma pequena quantidade (cerca de $100 \mathrm{~g}$ ) de palygorskita (PA), nos intervalos e bolsões/acumulação em que ocorria com maior freqüência. Para efeito de comparação, os resultados obtidos foram comparados com um padrão de palygorskita de Guadalupe, PI, [2]. Também foi adquirido um padrão de referência, amostra PFl-1 (Clay Minerals Soc., Florida, EUA), para realização das análises comparativas nos nossos laboratórios, nas mesmas condições e equipamentos das amostras de Alcântara.

Aproximadamente $1 \mathrm{~kg}$ de cada amostra foi submetido à secagem. Em seguida, foram desagregadas em almofariz de ágata e pulverizadas a 325 \# para posterior análise. As 8 amostras foram submetidas à difratometria de raios $\mathrm{X}$ (DRX), método do pó, em difratômetro PANalytical X'Pert Pro, equipado com tubo de $\mathrm{Cu}$ e filtro $\mathrm{k} \beta$ de $\mathrm{Ni}, 40 \mathrm{kV}$ e $30 \mathrm{~mA}$. Os registros foram realizados no intervalo $2 \theta$ de exposição de $5^{\circ}$ a $75^{\circ}$. No laboratório de sedimentologia foi realizada a separação granulométrica das amostras. A fração argila obtida foi usada na preparação de lâminas orientadas para análise de difração de raios X. Primeiro, cerca de 12 $\mathrm{g}$ do material foi peneirado em uma malha de $62 \mu \mathrm{m}$ por via úmida. Depois a fração síltico-argilosa restante foi centrifugada para que essas duas frações fossem separadas. Em seguida, a argila foi pipetada sobre lâmina de vidro em condições de temperatura ambiente, até a secagem total. Neste momento a lâmina passou por análise por DRX, para então ser saturada com etilenoglicol e em seguida ser aquecida a $550{ }^{\circ} \mathrm{C}$ por $2 \mathrm{~h}$. Após cada uma destas etapas, a 
amostra é novamente analisada por DRX.

As análises químicas foram feitas por FRX - pastilhas fundidas, em que cerca de $1 \mathrm{~g}$ de amostra pulverizada é misturado a $8 \mathrm{~g}$ de fundente tetraborato de lítio $\left(\mathrm{Li}_{2} \mathrm{~B}_{4} \mathrm{O}_{7}\right)$. Essa mistura é previamente submetida à homogeneização para melhor agregar a amostra. Em seguida essa mistura foi fundida a aproximadamente $1200{ }^{\circ} \mathrm{C}$ em um cadinho de platina.

A análise térmica (ATD/ATG) foi feita em equipamento Thermal Science PL com analisador térmico simultâneo Stanton Redcroft STA1000/1500, com forno cilíndrico vertical, conversor digital acoplado a um microcomputador, em uma faixa de temperatura entre a ambiente e $1100^{\circ} \mathrm{C}$.

Pequenas porções de palygorskita pura foram selecionadas para análise ao microscópico eletrônico de varredura. Essas amostras foram metalizadas com ouro, para permitir condutividade elétrica necessária no processo de formação das imagens através dos elétrons secundários. As imagens foram obtidas em um microscópico eletrônico de varredura Zeiss LEO 1430.

\section{RESULTADOS E DISCUSSÃO}

\section{Descrição do perfil}

$\mathrm{Na}$ falésia da praia da Baronesa é encontrada uma das principais exposições da Formação Alcântara, em que se observa uma alternância de pelitos, arenitos e dolomitos, ressaltadas pelas variações de cores bem acentuadas (Fig. 2). Nesta falésia foi confeccionado um perfil, no qual foram coletadas oito amostras (Fig. 3). Na base deste perfil são encontrados arenitos finos (amostra B-1) de coloração esverdeada, grãos de quartzo bem arredondados, esfericidade alta e bem selecionados. Apresentam estratificação cruzada complexa de pequeno e grande porte, com estruturas internas como laminações cruzadas cavalgantes, recobertas por filmes de argila. Acima do arenito, e ao longo de todo o perfil, ocorrem alternâncias de níveis de pelitos com porções ricas em silte e areia muito fina. Os pelitos apresentam variações de coloração esverdeada (amostras B-4 e B-6) e avermelhada (amostras B-2, B-5 e B-7), que é uma das feições mais características desse afloramento. Esses pelitos apresentam um argilomineral esbranquiçado, que ocorre distribuído praticamente em todo o perfil, na forma de concentrações

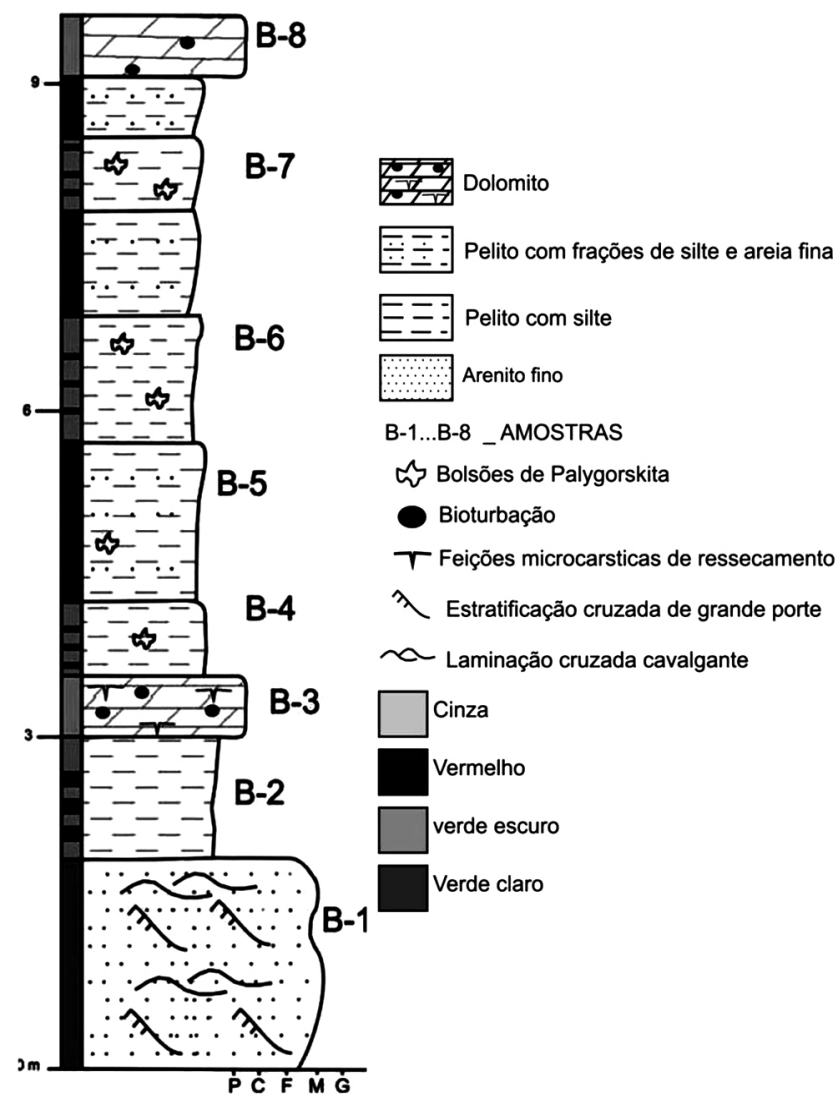

Figura 3: Perfil litológico da praia da Baronesa. [Figure 3: Lithologic profile at the Baronesa beach.]

esbranquiçadas e pequenas lentes. Esse mineral foi descrito como palygorskita, o que depois foi confirmado por DRX, conforme será descrito a seguir. Trabalhos já descreveram a ocorrência deste mineral como concreções dispersas em horizontes de paleossolo ou formando lâminas paralelas ao acamamento de depósitos argilosos [5, 6]. Níveis dolomíticos, que variam de 70 a $80 \mathrm{~cm}$, (amostras B-3 e B-8) ocorrem intercalados aos pelitos. Estes dolomitos são finos, de coloração branca a acinzentada, que apresentam uma espécie de macroporosidade preenchida por argila e bioturbações. Também exibem feições de superfícies microcársticas, raízes e micro brechas por ressecamento, que sugerem períodos em que provavelmente ocorreu emergência de água meteórica e pedogênese [7].

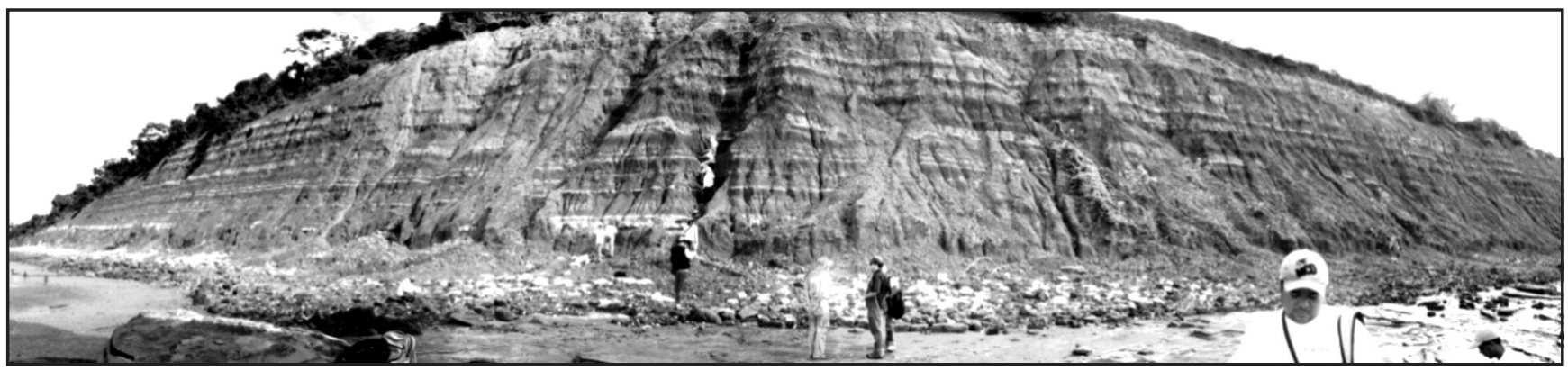

Figura 2: Falésia da praia da Baronesa.

[Figure 2: Baronesa beach cliff.] 


\section{Mineralogia da palygorkita}

A palygorskita é um argilomineral que ocorre com freqüência nos níveis pelíticos da praia da Baronesa, e aparece também associada aos níveis dolomíticos. Sua forma de ocorrência é como finas lentes intercaladas aos pelitos ou, mais freqüentemente, como bolsões ou acumulações centimétricas, nitidamente visíveis em afloramento, e cuja feição diagnóstica principal é a coloração branca e semelhança a um papel molhado (Fig. 4). A análise mineralógica dessas acumulações de palygorskita mostrou que esse mineral é a fase dominante (praticamente monominerálica), indicando somente traços de dolomita (Fig. 5).

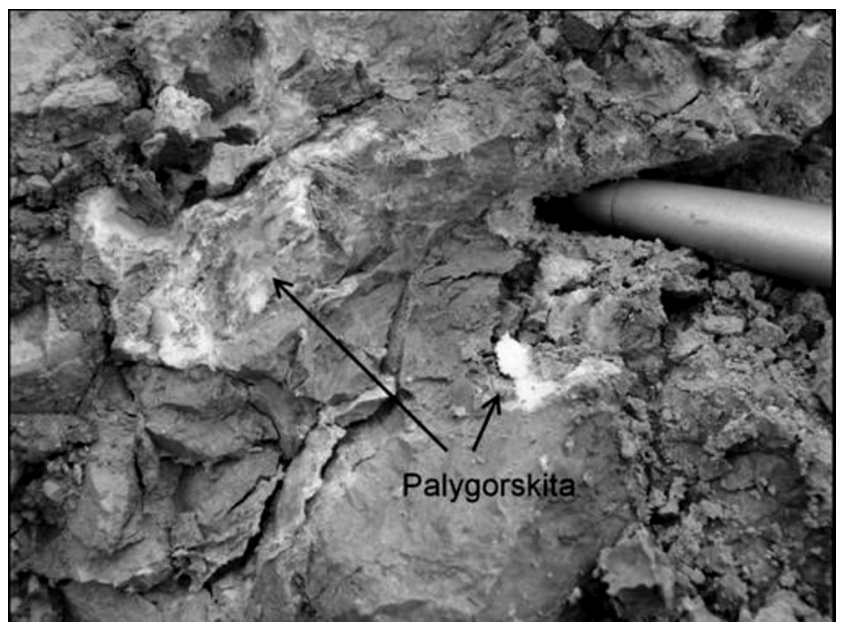

Figura 4: Palygorskita associada a níveis pelíticos esverdeados da praia da Baronesa.

[Figure 4: Palygorskite associated to green pelitic levels of Baronesa beach.]

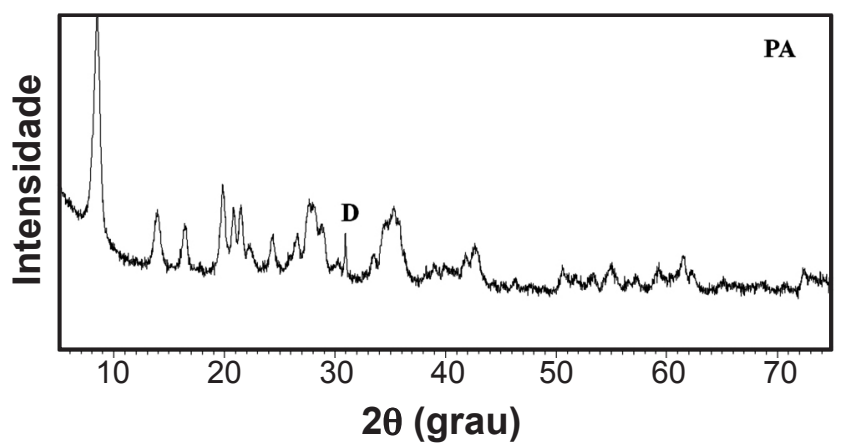

Figura 5: Difratograma de raios X da palygorskita de Alcântara, PA, demonstrando que é a fase dominante, com apenas o pico principal da dolomita (D) identificado.

[Figure 5: X-ray diffraction pattern of palygorskite from Alcântara, $P A$, Brazil, showing the dominance of this mineral, besides the main peak of dolomite (D) also described.]

\section{Mineralogia do perfil da praia da Baronesa}

A Fig. 6 apresenta a superposição de todos os difratogramas de raios $\mathrm{X}$ com a composição mineralógica das amostras analisadas do perfil da praia da Baronesa. A amostra B-1 é composta quase que exclusivamente de quartzo, mineral dominante do arenito fino da base do perfil. Porém, mesmo em pequenas quantidades, observa-se a presença do pico principal ou até mesmo mais de uma reflexão dos seguintes minerais: clorita, illita, palygorskita e traços de caulinita, que éperceptível apenas nas lâminas orientadas(Fig. 7). A amostra B-2 apresenta uma composição semelhante ao arenito da base, com menor teor de quartzo e maior conteúdo dos argilominerais, já descritos na amostra B-1. A amostra B-3 corresponde ao primeiro nível de dolomito que ocorre intercalado aos pelitos basais, constituída basicamente por dolomita, que é a fase dominante. A palygorskita ocorre nesta amostra como fase acessória. A amostra B-4, por encontrar-se sobrejacente ao nível dolomitico B-3, apresenta dolomita como fase dominante, seguida de palygorskita e quartzo, além de traços de mica e feldspato. Já as amostras B-5 e B-6 são muito semelhantes. A amostra B-5 apresenta a palygorskita em grande proporção, seguida de quartzo, illita, dolomita e traços de feldspato. E a amostra B-6 apresenta apenas a clorita como mineral distinto. É muito interessante ressaltar a ausência de esmectita na mesma, mostrando que os argilominerais dominantes nos pelitos são palygorskita e mica (illita). É de suma importância notar que ambas as amostras apresentam a palygorskita como fase dominante, com a notável ausência de argilominerais do grupo da esmectita, presente apenas na amostra B-2 (Fig. 7), que se admitia que fossem os argilominerais dominantes desses pelitos. Ou seja, a palygorskita não ocorre somente como as acumulações ou eflorescências esbranquiçadas observadas em afloramento, sendo a fase dominante da massa pelítica aflorante na falésia da praia da Baronesa. A amostra B-7 é constituída quase que exclusivamente de palygorskita, além de traços de quartzo, clorita, illita e hematita. O pico
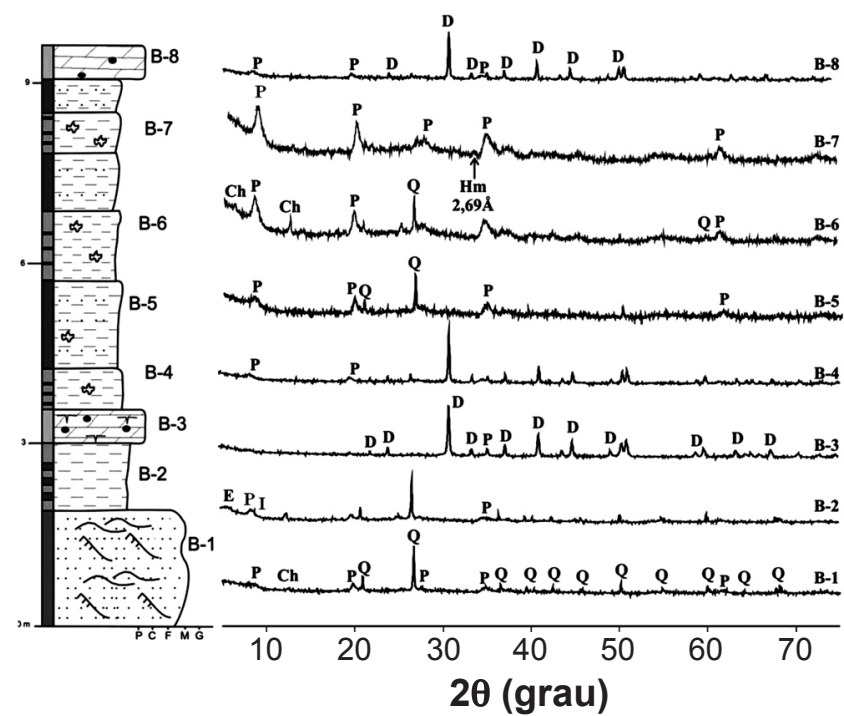

Figura 6: Perfil da praia da Baronesa, com amostragem e superposição dos difratogramas: palygorskita (P), esmectita (E), illita (I), quartzo (Q), dolomita (D), clorita (Ch) e hematita (Hm). [Figure 6: Baronesa beach profile, with indication of samples and $X$-ray diffraction patterns superposition. Palygorskite $(P)$, smectite $(E)$, illite (I), quartz (Q), dolomite (D), chlorite (Ch) and hematite $(\mathrm{Hm})$. 


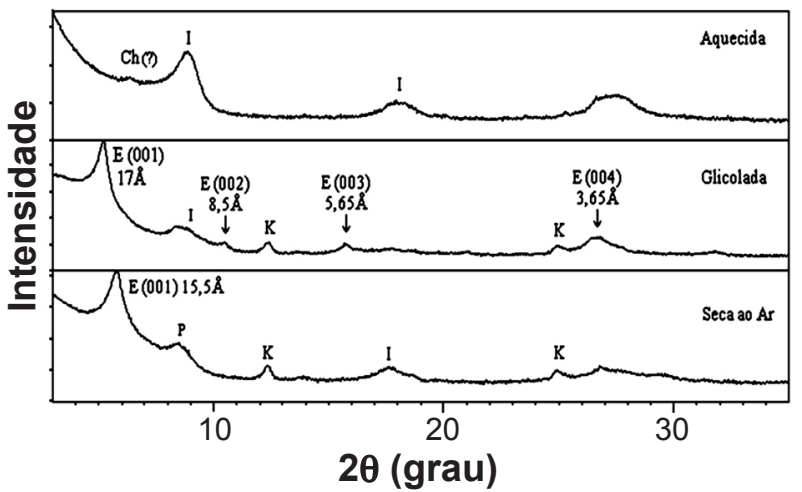

Figura 7: Difratograma da fração argila (B-2): Esmectita (E), palygorskita (P), illita (I), clorita (Ch) e caulinita (K).

[Figure 7: X-ray diffraction patterns of clay fraction $(B-2)$. Esmectite (E), palygorskite (P), illite (I), chlorite (Ch) and kaolinite $(K)$.]

principal da hematita está indicado, sendo que o mesmo é de pequena intensidade e, a princípio, seria o mineral responsável pela coloração avermelhada desses pelitos. Porém, admite-se que outros óxidos ou hidróxidos de ferro de baixa cristalinidade possam estar presentes, em pequenas quantidades, suficientes para "mancharem" o pelito da cor avermelhada, mas insuficientes para serem detectados pela DRX. O dolomito B-8, que ocorre no topo do perfil, é semelhante ao dolomito B-3 da base. Apresenta em sua constituição a dolomita como fase mineral dominante, e a palygorskita ocorre como fase acessória.

\section{Comportamento térmico da palygorskita}

A Fig. 8 apresenta os gráficos das análises termodiferencial e termogravimétrica da palygorskita de Alcântara (PA) e da palygorskita de referência PFL-1. É possível notar que as curvas apresentam certa semelhança, e a padrão clássico descrito na literatura [8]. Nas curvas de ATD, a posição dos principais picos endotérmicos é, praticamente, coincidente, nas duas amostras. A diferença principal está no alargamento dos mesmos (mais abertos na PFL-1), o que pode estar relacionado a um tempo maior de reação nesta amostra. O pico endotérmico principal acontece em torno de $110{ }^{\circ} \mathrm{C}$, relacionado a água adsorvida, e característico de outras palygorskitas [9]. Na amostra PF11 é nítida a presença de dois picos endotérmicos, como que representando dois estágios de perda de água: um a $\sim 75^{\circ} \mathrm{C}$ (umidade?) e outro a $\sim 110^{\circ} \mathrm{C}$ (água adsorvida, propriamente dita), enquanto na amostra PA esta separação não é tão bem delineada. Outras características das curvas de ATD são picos endotérmicos mais fracos, em aproximadamente $230^{\circ}$ $\mathrm{C}$ e $440{ }^{\circ} \mathrm{C}$, também descritos na literatura e relacionados à desidroxilação, além de outros picos endotérmicos mais fracos, em temperaturas mais elevadas. Neste último caso, apenas a PA apresenta um pico endotérmico fraco em 692 ${ }^{\circ} \mathrm{C}$. Acima desta temperatura, os picos exotérmicos de pequena intensidade, que aparecem de forma mais clara apenas na PFl-1 (em $\sim 886^{\circ} \mathrm{C}$ ). $\mathrm{Na} \mathrm{PA}$ estes picos não são claros, podendo, inclusive, se tratar de picos endotérmicos, relacionados a pequena quantidade de dolomita presente na amostra.

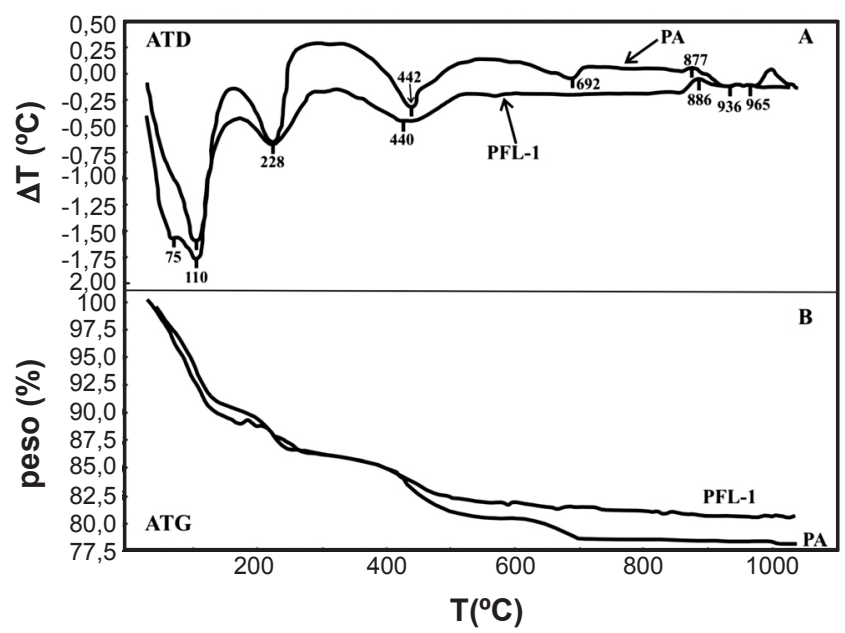

Figura 8: Curvas de análise termodiferencial (ATD) (A) e análise termogravimétrica (ATG) (B) da palygorskita de Alcântara (PA) e da palygorskita de referência PFL-1.

[Figure 8: Differential thermal analysis (DTA) and thermogravimetric analysis (TGA) curves of the palygorskite from Alcântara (PA) and PFL-1 reference.]

As curvas deATG também são bastante semelhantes, cujos pontos principais de inflexão refletem os picos endotérmicos principais descritos anteriormente. A diferença principal (o afastamento das duas curvas), se dá a partir de $\sim 450^{\circ} \mathrm{C}$. A partir deste ponto, a PFL-1 apresenta uma maior tendência a linearidade, com pouca perda de massa, chegando a cerca de $18 \%$ de perda de massa total. Já a PA, continua o processo de perda de massa, a inflexão em torno de $700{ }^{\circ} \mathrm{C}$ confirma o pico endotérmico descrito anteriormente na ATD, uma última aparente inflexão em torno de $1000{ }^{\circ} \mathrm{C}$ e perda de massa total, ao final, em torno de $23 \%$.

\section{Análise micromorfológica da palygorskita}

Ao MEV, a palygorskita dos bolsões ocorre como finas fibras entrelaçadas, em que os cristais estão levemente encurvados e alongados, como mostram as Figs. 9 A e B. Em outras porções, ela ocorre como finas fibras, formando uma espécie de teia, na qual os cristais encontram-se entrelaçados, como mostram as Figs. $9 \mathrm{C}$ e D.

No caso da palygorskita "maciça”, dos níveis pelíticos, como da amostra B-6, do perfil da praia da Baronesa (Fig. 10A), é muito interessante observar que, de fato, trata-se de níveis maciços. Porém, após a obtenção de um grande aumento ao microscópio eletrônico, foi possível observar o hábito acicular característico desse mineral (Fig. 10B), em dimensões extremamente reduzidas (nanométricas), finamente entrelaçadas, que conferem essa característica maciça (Fig. 10C). Portanto, a diferença principal entre os dois tipos de palygorskita, do ponto de vista micromorfológico, está na dimensão dos cristais aciculares, extremamente finos no nível pelítico/maciço (Fig. 10D). 

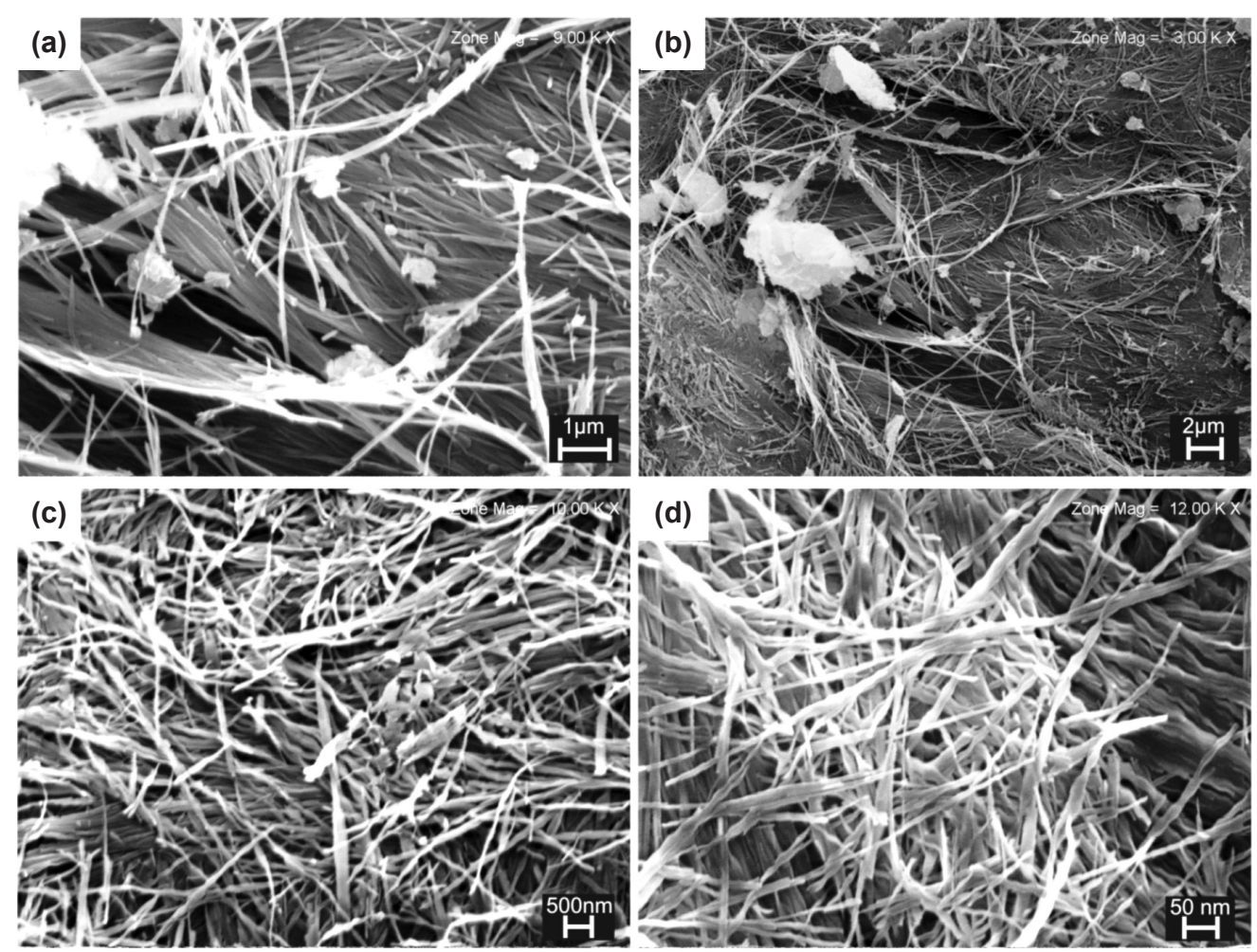

Figura 9: Imagem de elétrons secundários (MEV) da palygorskita dos bolsões/acumulações: cristais fibrosos e alongados levemente encurvados (a e b); cristais fibrosos entrelaçados com hábito em forma de teia (c e d).

[Figure 9: Secondary electron images of palygorskite from the accumulations: fibrous and elongated softly curved crystals (a and b); braided fibrous crystals with shaped habit ( $c$ and $d)$.]
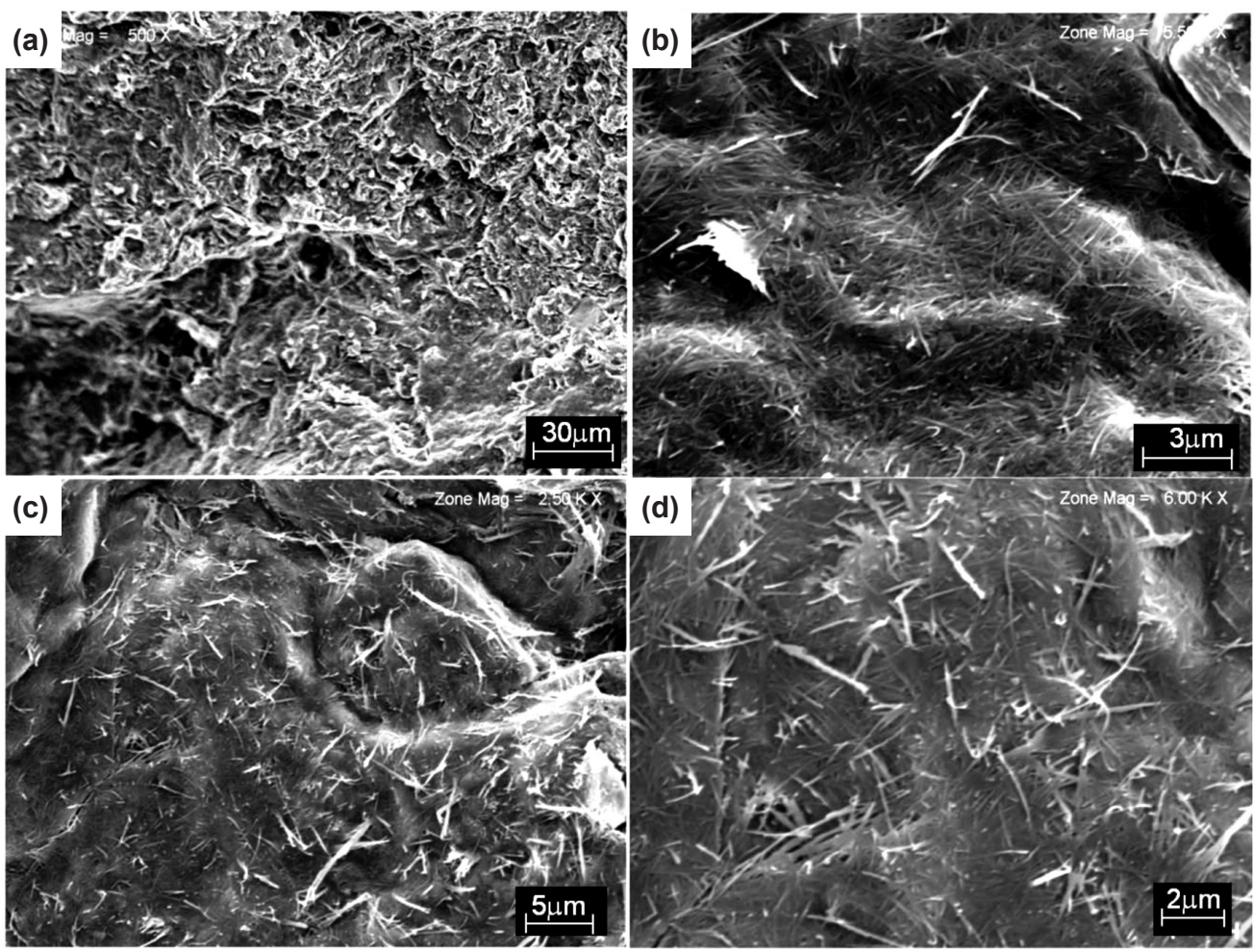

Figura 10: Imagem de elétrons secundários (MEV) da palygorskita maciça da amostra B-6: a) Pelito maciço; b) cristais aciculares na massa pelítica; c) acículas finas e entrelaçadas; d) acículas muito finas na massa pelítica.

[Figure 10: Secondary electron images of the massive palygorskite from sample B-6. a) Massive pelit; b) acicular crystals in the pelitic matrix; c) Fine and braided acicular crystals; d) very fine acicular crystals in the pelitic matrix.] 
Tabela I - Resultados da análise química por FRX do perfil da praia da Baronesa. [Table I - XRF chemical analysis of Baronesa beach profile.]

\begin{tabular}{ccccccccccccc}
\hline $\begin{array}{l}\text { Óxidos } \\
\begin{array}{l}\text { \% } \\
\text { Amostra }\end{array}\end{array}$ & $\mathrm{SiO}_{2}$ & $\mathrm{TiO}_{2}$ & $\mathrm{Al}_{2} \mathrm{O}_{3}$ & $\mathrm{Fe}_{2} \mathrm{O}_{3}$ & $\mathrm{MgO}$ & $\mathrm{MnO}$ & $\mathrm{CaO}$ & $\mathrm{Na}_{2} \mathrm{O}$ & $\mathrm{K}_{2} \mathrm{O}$ & $\mathrm{P}_{2} \mathrm{O}_{5}$ & $\mathrm{P.F}$ & $\mathrm{TOTAL}$ \\
\hline B-8 & 23,18 & 0,24 & 7,14 & 2,79 & 14,83 & 0,10 & 17,22 & 0,46 & 1,77 & 0,10 & 31,98 & 99,81 \\
$\mathrm{~B}-7$ & 50,96 & 0,52 & 15,67 & 7,51 & 5,90 & 0,07 & 0,69 & 0,22 & 3,56 & 0,16 & 14,73 & 99,99 \\
$\mathrm{~B}-6$ & 52,46 & 0,62 & 15,48 & 6,34 & 6,09 & 0,29 & 0,54 & 0,22 & 3,45 & 0,20 & 14,31 & 100 \\
$\mathrm{~B}-5$ & 53,56 & 0,76 & 15,06 & 7,83 & 4,08 & 0,30 & 0,67 & 0,39 & 4,14 & 0,16 & 13,05 & 100 \\
$\mathrm{~B}-4$ & 25,81 & 0,31 & 7,41 & 3,12 & 13,65 & 0,02 & 15,94 & - & 1,93 & 0,10 & 31,40 & 99,69 \\
$\mathrm{~B}-3$ & 7,01 & - & 2,02 & 0,78 & 20,08 & 0,09 & 26,96 & - & 0,46 & 0,04 & 42,33 & 99,77 \\
$\mathrm{~B}-2$ & 61,24 & 0,64 & 13,52 & 4,22 & 4,59 & 0,06 & 0,58 & - & 2,59 & 0,16 & 12,35 & 99,95 \\
$\mathrm{~B}-1$ & 61,31 & 0,60 & 13,17 & 5,91 & 3,84 & 0,10 & 0,37 & 0,65 & 3,03 & 0,14 & 10,84 & 99,96 \\
\hline
\end{tabular}

\section{Análises químicas}

Os resultados das análises das amostras do perfil da praia da Baronesa estão apresentados na Tabela I. De um modo geral, as amostras apresentam valores elevados de $\mathrm{SiO}_{2}(50,96 \%$ a $61,31 \%)$ relacionados com a maioria dos minerais identificados por DRX, palygorskita e quartzo, principalmente, além de illita, caulinita e clorita, em menores proporções. As amostras também apresentam teores elevados de $\mathrm{MgO}$, que juntamente com o $\mathrm{Al}_{2} \mathrm{O}_{3}$, podem ser o segundo ou terceiro elemento mais abundante. $\mathrm{O} \mathrm{MgO}$ desempenha um papel importante neste ambiente, pois também está relacionado aos minerais predominantes, identificada, dos argilominerais e da dolomita. Este mineral também é responsável pelos teores elevados de $\mathrm{CaO}$ nas amostras B-3, B-4 e B-8. Vale lembrar que não foi detectada calcita nestas amostras. Os teores de $\mathrm{Fe}_{2} \mathrm{O}_{3}$ são relativamente elevados, na maioria das amostras, devido à presença de hematita, identificada nas análises mineralógicas por DRX. A presença de $\mathrm{K}_{2} \mathrm{O}$ em quantidades relevantes está associada à ocorrência de illita em praticamente todas as amostras deste perfil. Traços de K-feldspatos também podem estar presentes. Os demais óxidos ocorrem em proporções menos significativas (teores inferiores a 1\%), como mostra a Tabela I.

\section{CONCLUSÕES}

Do ponto de vista sedimentológico, o perfil da praia da Baronesa apresenta forte associação com ambiente lagunar, interpretada a partir da predominância de pelitos e dolomicritos. Seu conteúdo mineralógico é representado por quartzo, palygorskita, dolomita, clorita, esmectita, illita, caulinita, calcita e traços de feldspatos. O predomínio de palygorskita e dolomita indicam que prevaleceu um ambiente mais fechado dominante, provavelmente com condições climáticas áridas a semi-áridas, grande disponibilidade de $\mathrm{Mg}$ e elevada taxa de evaporação. Estas seriam as condições ideais para a formação destes dois minerais. As análises químicas confirmam o conteúdo mineralógico, identificados por DRX, dos litotipos da área de estudo. Além disso, as análises químicas da palygorskita de Alcântara, em comparação aos padrões de referência, mostraram que ela apresenta teores mais elevados de $\mathrm{MgO}$. Vale ressaltar que parte destes valores estão relacionados à dolomita, assim como os de $\mathrm{CaO}$. Além dos novos resultados químicos e mineralógicos apresentados, considera-se que o presente trabalho traz importantes contribuições a respeito do conhecimento geológico da região, pois revelou a ocorrência de duas gerações de palygorskita. A primeira, palygorskita I, é maciça, está associada aos pelitos, identificada apenas por meio de difração de raios X. A segunda, palygorskita II, é observada como acumulações esbranquiçadas, visíveis a olho nu e admitidas como formadas posteriormente, ocorrendo na forma de eflorescências. Essa segunda geração de palygorskita não era conhecida, podendo constituir em níveis métricos e que podem revelar interesse econômico. A ocorrência de palygorskita na forma de níveis pelíticos maciços na falésia da praia da Baronesa revela que a análise de fácies pode ser usada como um guia prospectivo, pois, aliada à difração de raios $\mathrm{X}$, permite observar com detalhe a presença dos minerais e indica quais níveis apresentam maior concentração do mineral de interesse.

\section{AGRADECIMENTOS}

À ANP (Agência Nacional do Petróleo) e ao PRH-06 da Universidade Federal do Pará, os quais tornaram viável o início da realização deste trabalho. Ao Programa de Pós-Graduação em Geologia e Geoquímica - PPGG, Do Instituto de Geociências (IG) da UFPA e à Coordenação de Aperfeiçoamento de Pessoal de Nível Superior (CAPES), pela concessão de bolsa de mestrado à primeira autora. Ao $\mathrm{CNPq}$ pela concessão de bolsa de produtividade em pesquisa ao segundo autor (Proc. 304.566/2007-1). Ao Prof. Dr. Afonso Nogueira, do IG-UFPA, pelo incentivo e apoio nos trabalhos de campo e nas discussões geológicas. E à geóloga Joseanna Santos, pelas discussões a respeito do texto. 


\section{REFERÊNCIAS}

[1] D. F. Rossetti, W. Truckenbrodt, A. E. Santos Júnior, in A. M. Góes, D. F. Rossetti, W. Truckenbrodt, (Eds.), $O$ Cretáceo da Bacia de São Luis-Grajaú (2001) 67-76.

[2] A. B. Luz, S. L. M. Almeida, In: CETEM/MCT, RJ (2008) 223-238.

[3] S. Guggenheim, J. M. Adams, D. C. Bain, F. Bergaya, M. F. Brigatti, V. A. Drits, M. L. L. Formoso, E. Galán, T. Kogure, H. Stanjek, Clays and Clay Minerals, 54 (2006) 761-772.

[4] D. F. Rossetti, J. Sediment. Res. 68. (1998) 299-310.
[5] D. F. Rossetti, in M.L Costa, R. S. Angélica, (Eds.), Contribuições à Geologia da Amazônia (1997) 241-284.

[6] D. F. Rossetti, in A. M. Góes, D. F. Rossetti, W. Truckenbrodt, (Eds.) O Cretáceo da Bacia de São LuisGrajaú (2001) 32-34.

[7] D. F. Rossetti, in Simpósio sobre o Cretáceo do Brasil, 5, Boletim (1999) 485-489.

[8] W. Smykatz-Kloss, Applications of differential thermal analysis in mineralogy, Springer-Verlag, Berlim (1982) 152. [9] J. L. Post, S. Crawford, Appl. Clay Sci. 36 (2007) 232244.

(Rec. 05/11/2010, Rev. 16/02/2011, Ac. 02/03/2011) 